\title{
Age Differences in Online Communication: How College Students and Adults Compare in Their Perceptions of Offensive Facebook Posts
}

\author{
Loreen Wolfer, University of Scranton, U.S.A.
}

\begin{abstract}
With the most recent US Presidential election, civility in online communication has resurfaced as a social issue. Asurvey of 409 college students and 190 faculty / staff at a liberal arts college in northeastern Pennsylvania used open-ended questions to identify the types of communicative posts people of different ages have seen and considered offensive on Facebook. Content analysis identified twenty unique themes of online inappropriateness, many of whichare similar across age groups but do not appear in previous research. Common top themes include racist comments, sex / nudity, political references, and offending visuals. Age differences emerge in the rankings of these four themes and in the identified fifth theme, which is "other social issues" among college students and foul language for adults. Findings also indicate that students were statistically more likely than adults to consider posts involving traditional social issues (racism, sexism, LGBT issues, and alcohol / drugs) or aggression to be offensive; and, adults were more likely to consider foul language or the discussion of politics or religion to be offensive. Symbolic interaction theory is used to link perceptions of offensive posts to judgments of others, and suggestions for further research are discussed.
\end{abstract}

Keywords : content analysis, Facebook, college students, adults, inappropriate communication 


\section{Introduction}

Facebook is now thoroughly a part of mainstream culture. According to a recent PEW research study, $82 \%$ of young adults and $62 \%$ of the entire adult population use Facebook (PEW Research Center, 2015). For both younger and older Facebook users, Facebook mainly serves as a social outlet to keep in contact with friends and familyand to feel involved with others' lives (Brandtzæg, et al., 2010; McAndrew \& Jeong, 2012; Nadkarni \& Hoffman, 2012; Yang \& Brown, 2013). Leung (2013) found that social media, such as Facebook, also satisfied people's need to show affection, vent negative feelings, gain recognition, obtain entertainment, and broaden their knowledge base. However, there are age differences in Facebook use motivation. In addition to the entertaining element of Facebook, young adults, like college students,are more likely than more mature adults to use Facebook and other social network sites, like MySpace and Instagram, to practice selfexpression and to test different identities (Shoenberger \& Tandoc, 2014; Yang \& Brown, 2013). Online communication with friends helps young adults learn behavioral norms for their cohort and practice how they present those norms to others (Brandtzæg et al., 2010; Ehrenreich et al., 2014; Shoenberger \& Tandoc, 2014). For more mature adults, however, these purposes may be less relevant who primarily see Facebook as a source of entertainment (Leung, 2013).

Research has long been concerned with whether online communication is less civil than face-toface communication due to its more impersonal nature (Calhoon, 2000; Thorne, 2015). This has been especially evident in the 2016 United States presidential election. However, research generally ignores exactly what people consider to be offensive online and whether there are any differences in these perceptions based on various demographics, such as age. The limited research that does exist generally focuses on college students and their reactions to pre-selected online behaviors (Bazarova, 2012; Roche, et. al., 2015). At the time of this writing, there is no larger scale study of online communication that allows the respondents to self-identify what they consider to be offensive or that looks at age differences in these perceptions. This research is an attempt to fill this gap by examining: 1) the top five issues identified by college students and by adults as inappropriate for Facebook; and, 2) whether there are any statistically significant age differences in perceptions of inappropriate content overall. 


\section{Literature Review}

Younger and older people exhibit different behavioral norms in areas such as alcohol consumption, sexuality, nudity, and language both on and off-line. For example, many college students believe that college is a place to party and to drink alcohol (Lo, 2000; Marciszewski, 2006); and, students tend to think that visible participation in these behaviors is necessary to be socially accepted,even in a person does not participate in the behavior. Consequently young adults may be more likely than more mature adults to communicate these behaviors onlinein order to gain acceptance (Birmbaum, 2013; Brechwald \& Prinstein, 2011; Ehrenreichet al., 2014; Lo, 2000; Shinew \& Parry, 2005). There is some evidence for this. Peluchette and Karl (2007) studied 200 Facebook profiles and found that $42 \%$ had comments about alcohol and 53\% had photos about alcohol use. The same study looked at what people posted on each other's profiles and found that $50 \%$ of the posts involved partying. More mature adults may be less likely to feel peer pressure to drink alcohol or to post their experiences; and, therefore, may also be less inclined to feel that such behavior should be communicated online.

The view of appropriateness of sexuality and nudity in public may also be age relatedon and offline (Fix, 2016; Hestroni, 2007; Mayo, 2013; Potts \& Belden, 2009). Even though sexual behavior has become more visible, there is still controversyregarding where appropriate limits lie, and this is especially evident based on age. Younger Facebook users may be more tolerant of sex and nudity in public and online than those who are older; and, young adults, like college students, may communicate this by posting sexual references or nudity because they think that this is what their friends are doing or they think these behaviors are also expected to be "cool" (Ehrenreich et al., 2014; Goodmon et al.,2014; Peluchette \& Karl, 2007). Other behaviors, such as swearing, comments on different social issues, and how people present themselves online may also be age differentiated, as people of different ages may have different views on issues or different norms of self-presentation; however, this is not examined in an online environment (Chirico, 2014).

So far the existing research, limited as it is, focuses on college students. For example, Bazarova (2012), in a study of 226 college students,found that students viewedhighly intimate or tragiconline disclosures astoo much sharing, and therefore, were inappropriate. Roche and colleagues (2015) 
furthered this study by asking 150 college students to react to the level of appropriateness of mock Facebook feeds created after an informal poll of 20 college students. These feeds focused on romantic relationship drama, negative emotion, passive aggression, and frequent status updates. The findings revealed that posts involving relationship drama were perceived as the most inappropriate, followed by passive aggressive posts. These findings support those of Brandtzæg and colleagues (2010) regarding the self-disclosure norm violation of sharing too much, as personal information sharing in public is dubbed "too much information" or "TMI". However, according to their findings, negative emotion posts, frequent status updates and neutral posts were all deemed as relatively appropriate.

While an important step, these studies are limited in a few ways. First, they all involve college students' perceptions. However, many college students are Facebook friends with other individuals, especially family members and co-workers and therefore need to communicate with people in a variety of different networks. Because the norms of college behavior differ from adult norms in many ways, perceptions of what is appropriate to communicate on Facebook and how may differ as well; but, this is unstudied. Second, the methods of previous studies generally involve hypothetical Facebook walls or posts. Both Bazarova (2012) and Roche and colleagues (2015) use quantitative analyses of student reactions to hypothetical researcher created Facebook posts or feeds. Therefore, the type of topic covered was decided by the researcher. Roche and colleagues (2015) did pick their topics after an informal poll of 20 students; but, this approach, while an improvement over purely researcher driven scenarios, isstill limited. Twenty students is a very small sample and may be biased. A larger sample of students may identifynew topics considered to be inappropriate for Facebook, but this is unable to be examined when researchers select the posts to be studied. Wolfer (2016), using focus groups who did not respond to preconceived scenarios, built on Roche's and Bazarova's studies by taking a more qualitative approach to determining what college students identified as inappropriate online communication. Wolferfound that college students also felt that negative comments about social issues, such as race and gay marriage, or communications that were purposely embarrassing or mean were inappropriate on Facebook. While Wolfer's study did build on these previous ones by being qualitative and by identifying additional themes of inappropriateness, her study is vulnerable to the same limitation 
of Bazarova's (2012) and Roche and colleagues (2015) of only considering college students; and, additionally, by using focus groups, it is limited to a small sample of only 46 college students.

The desire to use Facebook to stay connected with friends and family, to foster interpersonal relationships in many different contexts (family, friends, work), and to present a positive selfimage to others, all in the context of the diverse social networks common on Facebook, point to the importance of understanding what types of Facebook posts users of different ages view as inappropriate. From a symbolic interactionist framework, people rely on the symbolic meanings of their interaction with others to learn the appropriate behavior for their group and these interpretations are situationally dependent (Blumer, 1969; Thomas, 1931). People will act towards others based on the identified situation and the corresponding meanings that they attribute to other's actions and communication in that situation (Blumer, 1960; Thomas, 1931). When consensus in situations is high, the meaning of the symbol communicated is clear; when consensus is low, the meaning becomes ambiguous and communication becomes problematic (Thomas, 1931). Given the diverse age networks on Facebook and the ways people of different ages use Facebook, people's attributed meanings in online communication may also differ.

This is especially relevant because researchers have found that sharing even a small amount of negatively perceived information leads to a negative view of the individual doing the sharing (Goodmon et al., 2014; Steeves \& Regan, 2014). However, as mentioned previously, studies of perceptions on Facebook inappropriatenessonly focus on college students. An examination of the literature at the time of this writing revealed no studies focusing on what adult Facebook users see and interpret as inappropriate communication on Facebook. Adults frequently use Facebook not only to follow other people's lives, but also to keep tabs on their children, who may be posting behaviors to impress their peers, but which are contrary to the values adults tried to instill (Brandtzæg et al., 2010; Steeves\& Regan, 2014). Furthermore, adult Facebook users may be coworkers or people who may serve as professional social networks for younger Facebook users; therefore, identifying inappropriate posts may also have long term benefit to individuals, especially younger Facebook users. When the absence of physical communication clues are coupled with the diverse types of relationships in online social networks and the potential differences in norms 
of age appropriate communication, the possibility of misinterpretation for online communication is potentially high; and, therefore, so is possible negative judgments about individuals online.

Therefore, in sum, limiting evaluation to hypothetical scenarios risks failure to identify other topics that Facebook users may deem inappropriate. A more qualitative approach provides Facebook users the opportunity to identify and express, in their own words, what they feel is inappropriate types of online communication. This may lead to identifying additional inappropriate topics as Wolfer's (2016) small study began to do. As previously mentioned, there is also no research examining this topic among adult Facebook users. Given the controversies over appropriate levels of public displays of sex / nudity, foul language,social issues, and political views, adults may be more likely to consider some topicsas inappropriate forFacebook than college students. To address these gaps, this study compares what peoplehave seen on Facebook and consider to be inappropriate based on age. Specifically, this study has two research purposes: 1) to identify the top five posts identified by college students and by adults as inappropriate for Facebook; and, 2) to see whether there are any statistically significant age differences in perceptions of inappropriateness overall.

\section{Methods and Sample}

An online survey via a Survey Monkey link was administered to a population of undergraduate students $(n=3,713)$, faculty $(n=306)$, and staff $(n=610)$ at a small liberal arts college in northeastern Pennsylvania regarding their Facebook experiences. The student response rate was $14.1 \%(n=572)$ and the faculty / staff response rate was $20.8 \%(n=190)$, which is less than desirable. Like the university from which the data was collected, the majority of both the student and the adult sample is female (66.7\% of students, $72.9 \%$ of adults) and white $(81.9 \%$ of students, $93.7 \%$ of adults). The majority of the student sample is freshmen (35.3\%), followed most commonly by seniors $(22.5 \%)$, sophomores $(22 \%)$, and juniors $(19.5 \%)$. The majority of the adult sample is between 45-54 years old (28.9\%), followed by 55-64 years old (24.2\%). Three quarters of the adult sample has at least a four year college degree $(75.8 \%)$. 
More than three quarters of the student respondents (78.7\%) and all but one of the adult respondents had a Facebook account at the time of the study. Similar proportions of students and adults report being on Facebook multiple times a day (54.4\% of students and 53.2\% of adults). Of the 572 responding students, 409 of them listed at least one inappropriate issue they saw on Facebook, while all of the 190 faculty / staff made some type of comment describing this. Less than $10 \%$ of both students and adults (1.2\% of students and $7.9 \%$ of adults) claim that they have never seen any offensive Facebook posts.

\section{Design}

The survey asked about their Facebook usage, some brief demographic variables, and included an open ended question askingrespondents to describe the three most offensive posts that they have seen on Facebook. This qualitative open ended wording allowed the respondents to identify both their experiences and their perceptions of Facebook posts. This qualitative approach allows individuals to provide a rich description of their subjective, unrestricted understanding of a phenomenon, which in this case is generally absent in the literature (Birnbaum 2013). Institution Review Board approval was obtained and the respondentsfrom each of the three categories were offered a chance to win one of three Kindle Fires for study participation. Surveys and respondents were tracked separately by unique identifiers which enabled the researcher to know what students, faculty, and staff responded to the study, but did not allow the researcher to link respondents to individual survey responses. Even though colleg students are young adults, for ease of writing, they are referred to as either "younger Facebook users" or "students", while the faculty and staff will be collectively referred to as "adults".

This research utilizes open coding where descriptive labels were written for every reference of inappropriate post seen on Facebook. First the author read through all responses and color coded like statements into themes, simultaneously making a codebook. Individual respondents received a " 1 " if a comment related to a particular theme in the codebook and a " 0 " if it did not.

Sometimes two or more comments received only one code. For example, when listing the top three offensive posts seen, if an individual put "comments about gays" as one comment and 
"comments about transgender individuals" as a second comment, they both apply to lesbian / gay / bisexual / transgender individuals (LGBT), so even though there are two comments, they can only receive one code of "1" for the theme "LGBT issues". Similarly, some comments may have received more than one code. For example, a response of "racist comments against President Obama" would receive both a "1" for the theme of "racism" and a "1" for the theme of "politics" (since there is a specific reference to the President). Furthermore, not all respondents identified three examples; some identified only two. Based on this, 20 different themes emerged and examples of the comment types appear in Table 1.

A second independent evaluator coded the same data using the coding themes developed. Interrater reliability was established via Cohen's kappa since the themes were categorical in nature. Originally 10 of the 20 items had a Cohen's kappa of .8 or higher indicating very strong interrater reliability (McHugh, 2012; Viera \& Garrett,2005). For the remaining 10 categories, the raters discussed the areas of individual areas of discrepancy for each respondent until agreement in coding was reached and changed accordingly on the master data set. The mutually decided themes have a Cohen's kappa of 1 since they were discussed until agreement was reached. The respective Cohen's kappa for each theme also appears in Table 1. 
Table 1. Coded themes in alphabetical order with select examples of content and Cohen's kappa values

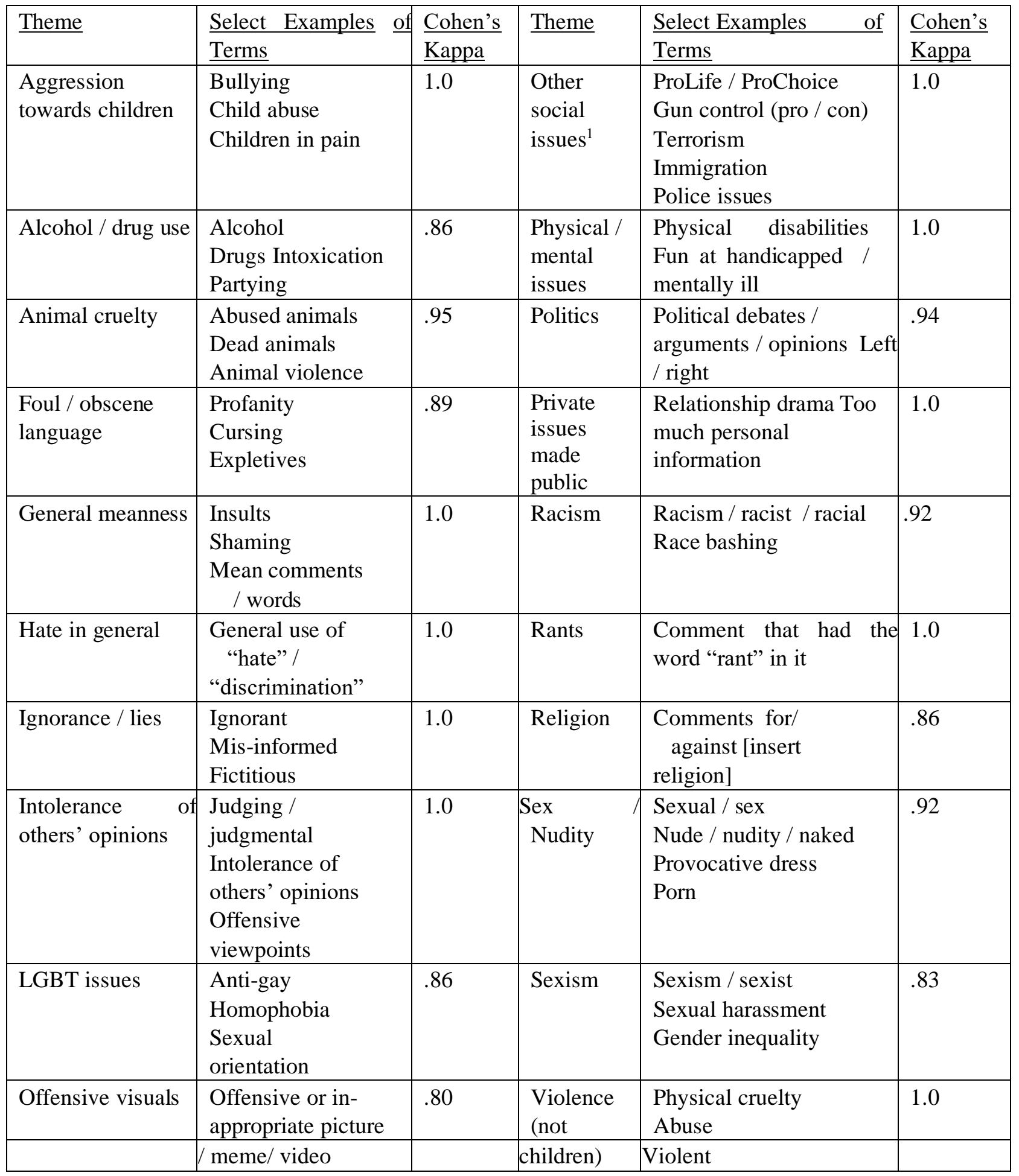

\footnotetext{
${ }^{1}$ This category individual to social issues that did not have enough observations to warrant their own category.
} 


\section{Results}

\section{Research Question 1: Top Five Inappropriate Themes}

For the most part, students and adults do not differ in their identification of the top five themes they have seen on Facebook and deem inappropriate, even though they may differ in the relative rankings of the five. The top five themes students have seen and consider to be inappropriate are: racism $(35.9 \%, \mathrm{n}=147)$, sex / nudity $(25.9 \%, \mathrm{n}=106)$, politics $(18.3 \%, \mathrm{n}=75)$, offensive visuals $(16.6 \%, \mathrm{n}=68)$, and "other social issues" $(16.4 \%, \mathrm{n}=67$, Table 2$)$. For the adults, the top five themes are: sex / nudity $(28.4 \%, \mathrm{n}=54)$, politics $(26.3 \%, \mathrm{n}=50)$, foul language $(21.6 \%, \mathrm{n}=41)$, racism $(21.1 \%, \mathrm{n}=40)$, and offensive visuals $(15.8 \%, \mathrm{n}=30)$. Therefore four of the top five themes (racism, sex / nudity, politics, and offending visuals) appear in the top five for both groups even though the number one for the two groups differ. However, students were more likely to mention seeing inappropriate presentations of various social issues (beyond those which are their own category) in their top fivethan the adult sample, and the adults were more likely to see and consider foul language on Facebook to be inappropriate. 
Table 2. College Students and Adult Perceptions of Inappropriate Facebook posts: Rankings and ChiSquare Tests for Significance

\begin{tabular}{|c|c|c|c|c|c|}
\hline Inappropriate Topic & College Stud & & Faculty / St: & & \\
\hline & $\%(\mathrm{n})$ & Rank & $\%(\mathrm{n})$ & Rank & \\
\hline Racism & $35.9 \%(147)$ & 1 & $21.1 \%(40)$ & 4 & $p<.01$ \\
\hline Sex / nudity & $25.9 \%(106)$ & 2 & $28.4 \%(54)$ & 1 & \\
\hline Politics & $18.3 \%(75)$ & 3 & $26.3 \%(50)$ & 2 & $p<.05$ \\
\hline Offensive visuals & $16.6 \%(68)$ & 4 & $15.8 \%(30)$ & 5 & \\
\hline Other social issues & $16.4 \%(67)$ & 5 & $9.5 \%(18)$ & 8 & $\mathrm{p}<.05$ \\
\hline Aggression towards children & $16.1 \%(66)$ & 6 & $6.8 \%(13)$ & 10 & $\mathrm{p}<.01$ \\
\hline General meanness & $14.2 \%(58)$ & 7 & $10 \%(19)$ & 7 & \\
\hline Sexism & $13.8 \%(56)$ & 8 & $5.9 \%(11)$ & 11 & $\mathrm{p}<.01$ \\
\hline Foul / obscene language & $11.5 \%(47)$ & 9 & $21.6 \%(41)$ & 3 & $\mathrm{p}<.01$ \\
\hline Violence (not children) & $10.5 \%(43)$ & 10 & $3.7 \%(7)$ & 13 & $\mathrm{p}<.01$ \\
\hline LGBT issues & $10.3 \%(42)$ & 11 & $4.2 \%(8)$ & 12 & $\mathrm{p}<.05$ \\
\hline Animal cruelty & $7.6 \%(31)$ & 12 & $8.9 \%(17)$ & 9 & \\
\hline Hate in general & $6.1 \%(25)$ & 13 & $6.8 \%(13)$ & 10 & \\
\hline Intolerance of other's opinions & $5.9 \%(24)$ & 14 & $3.7 \%(7)$ & 13 & \\
\hline Private issues made public & $5.4 \%(22)$ & 15 & $6.8 \%(13)$ & 10 & \\
\hline Religion & $5.1 \%(21)$ & 16 & $11.1 \%(21)$ & 6 & $\mathrm{p}<.01$ \\
\hline Alcohol / drug use & $5.1 \%(21)$ & 16 & $1.1 \%(2)$ & 15 & $\mathrm{p}<.05$ \\
\hline Ignorance / lies & $4.9 \%(20)$ & 17 & $6.8 \%(13)$ & 10 & \\
\hline Physical / mental issues & $2.7 \%(11)$ & 18 & $1.6 \%(3)$ & 14 & \\
\hline Rants & $1.5 \%(6)$ & 19 & $4.2 \%(8)$ & 12 & $\mathrm{p}<.05$ \\
\hline
\end{tabular}

There are other age differences as well further down the rankings. For example, religion, general comments of hate, animal cruelty, private issues made public, and posts that the reader interprets as ignorant or lying appear in the top 10 for adults, but not for college students. Similarly, violence appears in the top 10 for college students, but not for adults. This suggests that while some topics are so inappropriate for Facebook they are agreed upon by both students and adults, differing age norms do exist.

\section{Research Question 2: Statistically Significant Age Differences}

While respondents may, for the most part, agree on the top five offensive themes, this does not necessarily mean that they agree to the same degree. Chi-square analysis reveals that college students identified a greater number of overall themes witnessed and deemed inappropriate than 
the older cohort. Of the 11 themes where statistically significant age differences emerged, college students were more likely to identify seven of them as inappropriate. For example, college students are more likely than adults to consider Facebook posts relating to specific traditional social issuesto be inappropriate. Students were statistically more likely than older adults to see and be offended by posts about racism $(35.9 \%$ compared to $21.1 \%$, p<.01, Table 2$)$, sexism $(13.8 \%, 5.9 \%$, p<.01), LGBT issues $(10.3 \%, 4.2 \%, \mathrm{p}<.05)$, alcohol / drugs $(5.1 \%, 1.1 \%, \mathrm{p}<.05)$, and "other social issues" $(16.4 \%, 9.5 \%, \mathrm{p}<.05)$. College students are also more likely than adults to see and be offended by posts indicating some type of aggression or violence. College students were twice as likely to see posts about aggression to children that they find offensive (16.1\%) compared to adults $(6.8 \%$, $\mathrm{p}<.01)$. Likewise, 1 in 10 college students have seen some type of violent post $(10.5 \%)$ where less than half of that $(3.7 \%, \mathrm{p}<.01)$ of adults claim the same.

On the other hand, adult Facebook users were more likely to see and define posts that relate to other types of controversy, such as political discourse or foul language to be inappropriate. Almost one quarter of adults (26.3\%) compared to less than $20 \%(18.3 \%)$ of college students ( $\mathrm{p}<.05)$ saw political posts that they claimed were inappropriate. Furthermore, adults were twice as likely $(21.6 \%)$ than students $(11.5 \%, \mathrm{p}<.01)$ to see and consider foul language on Facebook to be inappropriate. Adults were also more likely to see and define posts involving religion(11.1\% compared to $5.1 \%, \mathrm{p}<.01)$ or posts that were "rants" as inappropriate $(4.2 \%$ compared to $1.5 \%$, $\mathrm{p}<.05)$.

\section{Discussion}

The concern for civility and appropriate onlinecommunication is not new (Calhoon, 2000; Thorne, 2015). Given Facebook's popularity, the diverse social networks on Facebook, and the variability in normative behavior across groups, different groups of people are likely to consider different behaviors on Facebook to be offensive. What these behaviors are though is unclear and generally un-studied. This is an significant topic because negative interpretations of Facebook posts can translate into negative judgments about the posting individual. Therefore it is important to know if and how perceptions of inappropriate communication on Facebook vary, especially by age (Goodmon et al., 2014; Steeves \& Regan, 2014). 
This research adds to the existing literature by qualitatively examining self-identified themes of inappropriate posts by younger (college students) and older (faculty / staff) Facebook users and whether there are statistical differences based on age between these perceptions. The most notable finding is that what people, regardless of age, define as inappropriate Facebook communication are themes that are generally missing in the scant existing literature. This identification of new themes supports a qualitative approach that allows respondents to attribute their own meaning to their interactions.

Second, contrary to obvious age differences in face-to-face behavior in various areas (Fix, 2016; Mayo, 2013; Potts \& Belden, 2009), the findings here suggest that younger and older Facebook users share similar definitions of inappropriateness for online communication. Four of the top five themes identified - race, sexuality / nudity, politics, and offensive visuals - are common to both age groups. This similarity is remarkably consistent when considering that these were selfidentified topics that were not prompted by the researcher.

Nevertheless, similar does not mean equal. Age differences did emerge. For example, college students were more offended by communication about additional ("other") social issues than were adults and adults were more likely than college students to consider foul language on Facebook to be inappropriate, the latter of which is supported by research in face-to-face interaction (Chirico, 2014). Statistically the younger cohort, possibly contrary to expectations, also identified a greater number of themes witnessed and deemed inappropriate examples of online communication than did the older cohort. Students were more likely than older adultsidentify posts about racism, sexism, LGBT issues, and alcohol / drugs as inappropriate. These differences are not comple tely unexpected as they mirror the types of issues frequently discussed and analyzed on college campuses. If, as Shoenberger and Tandoc (2014) argue, college students use Facebook to explore their views and try and influence others, then it follows that their posts may reflect material that they are encountering in their classes. Research here and by Wolfer (2016), however, suggests that using Facebook to test one's views or influence others about issues learned on campus, may 
not be well-received by others, especially peers, since these types of communicative posts were deemed inappropriate on Facebook.

On the other hand, adult Facebook users were statistically more likely to see and define posts regarding political discourse, foul language, religious views, or posts that were "rants" as inappropriate. Age differences involving the use of foul language and rants suggests that adults have different norms for self-presentationin online communication than do college students (Chirico, 2014). While no research has examined people's views of rants on or off-line, it is feasible to link rants to inappropriate self-presentation, given that Facebook, especially among older individuals, is generally used for more entertaining purposes (Leung, 2013). The finding regarding politics is less clear. On the one hand, adults are more likely than college students to vote (File 2013); but according to Carlisle and Patterson (2013), they do not use Facebook extensively for political discussion. Therefore, it may be that adults, given their voting interests, are particularly likely to see politics as controversial and, therefore a violation of Facebook's "real" purpose of entertainment (Leung, 2013). However, this should be examined further in future research.

From a symbolic interactionist view, for the most part, younger and older Facebook users attach similar meanings of inappropriateness toonline communication that involves expression of racism, sex / nudity, offensive visuals, and politics on Facebook, thereby leading to consensus in communication. However, there are areas where the meaning attributed to Facebook posts are less clear, most notably foul language and social issues beyond the traditional ones ("other social issues"). Given the diversity of online social networks, users needs to be sensitive to what others who are different than them (here based on age) attribute negative meaning to because negative interpretations of communication lead to negative perceptions of the individual doing the communicating / posting (Goodmon et al., 2014; Oldmeadowet al., 2013; Steeves\& Regan, 2014).

In summary, this research contributes to the existing literature in a number of ways. First, this research is qualitative and respondent driven so it identified many themes of inappropriate communication that previous studies have not. Second, it includes a previously unexplored 
population - adult Facebook users. Third, this research compares the views of a younger population who grew up with social media to an older one who has not; and, it has found that while there are many similarities in perceptions of offensive online communication, differences in these and other previously unexplored themes emerge as well. From a symbolic interactionist perspective this is important for online communication because people's online networks are likely to be socially and culturally diverse; and, for successful communication, members of social networks needs to be aware of the different meanings others attribute to their online posts.

Because research into views of Facebook inappropriateness is relatively new for college students and unexplored for adults, if done again, there are some areas where this research could be improved. One suggested change is to separately examine what people may find offensive with what they have actually seen. This may better disentangle the differences between perception and observation. This would involve first posing various topics or scenarios indicating potentially offensive postsand asking the people to react to them, much like researchers of adolescents have done (Bazarova, 2012; Roche et al., 2015), but expanding the topics of these posts given the findings of this study. This can be followed with asking respondents whether they have actually seen any of the posts described.Second, future research might want to explore why people of different ages find these types of posts inappropriate. This will give more insight to understanding the dynamics between Facebook motivation (e.g. entertainment and social connectedness) and emerging values involved inFacebook use. Last, this sample and the population from which it was drawn are rather homogenous in terms of race and gender; and, has a relatively low response rate. Using a qualitative approach with a different population may identify other themes or suggest more group differences in themes that Facebook users deem to be inappropriate. 


\section{References}

Bazarovca, N. (2012). Public Intimacy: Disclosure Interpretation and Social Judgments on Facebook. Journal of Communication, 62(5), 815-832. https://doi.org/10.1111/j.14602466.2012.01664.x

Brandtzæg, P. B., Lüders, M., \&Skjetne, J. H. (2010).Too many Facebook "friends"? Content sharing and sociability versus the need for privacy in social network sites. International. Journal of Human-Computer Interaction, 26(11-12), 1006-1030. https://doi.org/10.1080/10447318.2010.516719

Brechwald, W., \& Prinstein, M. (2011). Beyond homophily: A decade of advances in understanding peer influence processes. Journal of Research on Adolescence, 21(1), 166179. https://doi.org/10.1111/j.1532-7795.2010.00721.x

Calhoun, C. (2000). The Virtue of Civility. Philosophy and Public Affairs, 29(3), 251-275. https://doi.org/10.1111/j.1088-4963.2000.00251.x

Chirico, R. (2014). Damn!: a cultural history of swearing in modern America. North Carolina: Pitchstone Publishing.

Ehrenrich, S. E., Underwood, M.K., \& Ackerman, R.A. (2014). Adolescents' Text Message Communication and Growth. Antisocial Behavior Across the First Year of High School. Journal of Abnormal Child Psychology, 42, 251-264. https://doi.org/10.1007/s10802-0139783-3

FileThom.(2013). Young-Adult Voting: An Analysis of Presidential Elections, 1964-2012. Current Population Survey Reports, P20- 572.U.S. Census Bureau, Washington, DC. Retrieved on July 30, 2016 from https://www.census.gov/prod/2014pubs/p20-573.pdf

Fix, M. P. (2016). A universal standard for obscenity? The importance of context and other $\begin{array}{lllll}\text { considerations. } & \text { Justice } & \text { System } & \text { Journal, } & 37(1),\end{array}$ https://doi.org.ezp.scranton.edu/10.1080/0098261X.2015.1042601

Goodmon, L. B., Smith, P. L., Ivancevich, D., \& Lundberg, S. (2014). Actions speak louder than personality: Effects of Facebook content on personality perceptions.North American Journal of Psychology, 16(1), 105-119. Retrieved from http://search.proquest.com/docview/1509047156? accountid=28588 
Hetsroni, A. (2007). Sexual content on mainstream TV advertising: A cross-cultural comparison. Sex Roles, 57(3-4), 201-210. https://doi.org.ezp.scranton.edu/10.1007/s11199-007-9247-8

Hilsen, A. I., \& Helvik, T. (2014). The construction of self in social medias, such as Facebook.AI \& Society, 29(1), 3-10. https://doi.org.ezp.scranton.edu/10.1007/s00146-012-0426-y

Ho, S. S., \& McLeod, D. M. (2008). Social-psychological influences on opinion expression in face-to-face and computer-mediated communication. Communication Research, 35(2), 190-207. https://doi.org/10.1177/0093650207313159

Leung, L. (2013). Generational differences in content generation in social media: The roles of gratficiations sought and narcissism. Computers in Human Behavior, 29(3), 9971006. https://doi.org/10.1016/j.chb.2012.12.028

Lo, C. (2000). The Impact of First Drinking and Differential Association on Collegiate Drinking. $\quad$ Sociological 265-280. https://doi.org/10.1080/00380237.2000.10571170

Marciszewski, A. (2006). Peer Persuasion: Universities Turn to Students to Help Battle Alcohol Abuse. Tulsa World. Retrieved on June 1, 2014 from http://search.proquest.com/docview/ 400056383 ? accountid $=28588$

Mayo, C. (2013). Unsettled Relations: Schools, Gay Marriage, And Educating for Sexuality. Educational Theory, 63(5), 543-558. Retrieved from http://rose.scranton.edu.ezp.scranton.edu/login?url=http://search.proquest.com.ezp.scrant on.edu/docview/1449830521 ?accountid=28588

McAndrew, F. T., \& Jeong, H. S. (2012). WhoDoes What on Facebook? Age, Sex, and Relationship Status as Predictors of Facebook Use. Computers In Human Behavior, 28(6), 2359-2365. https://doi.org/10.1016/j.chb.2012.07.007

McHugh, M. L. (2012). Interrater reliability: the kappa statistic. BiochemiaMedica, 22(3), 276282. https://doi.org/10.11613/BM.2012.031

Miller, P. R., Bobkowski, P. S., Maliniak, D., \& Rapoport, R. B. (2015). Talking politics on Facebook: Network centrality and political discussion practices in social media. Political Research Quarterly, 68(2), 377-391. https://doi.org/10.1177/1065912915580135

Nadkarni, A., \& Hofmann, S. G. (2012). Why do people use Facebook? Personality and Individual Differences, 52(3), 243-249. https://doi.org/10.1016/j.paid.2011.11.007 
Oldmeadow, J. A., Quinn, S., \& Kowert, R. (2013). Attachment style, social skills, and Facebook use amongst adults. Computers in Human Behavior, 29(3), 1142-1149. https://doi.org/10.1016/j.chb.2012.10.006

Peluchette, J. V., \& Karl, K. A. (2007). The prevalence of Facebook faux pas and students' “devil may care" attitudes. In Midwest Academy of Management Meeting, Kansas City, Missouri, October 4th-6th.

PEW Research Center, (2016). Mobile messaging and social media 2015, March 17- April 12, 2015, retrieved in July 18, 2016).

Potts, R., \& Belden, A. (2009). Parental guidance: A content analysis of MPAA motion picture rating justifications 1993-2005. Current Psychology, 28(4), 266-283. https://doi.org.ezp.scranton.edu/10.1007/s12144-009-9065-y

Roche, T. M., Jenkins, D. D., Aguerrevere, L. E., Kietlinski, R. L., \& Prichard, E. A. (2015). College Students' Perceptions of Inappropriate and Appropriate Facebook Disclosures. Psi Chi Journal of Psychological Research, 20(2), 86-96. https://doi.org/10.24839/2164-8204.JN20.2.86

Shinew, K., \& Parry, D. (2005). Examining College Students' Participation in the Leisure Pursuits of Drinking and Illegal Drug Use. Journal of Leisure Research, 37(3), 364-387. https://doi.org/10.1080/00222216.2005.11950058

Shoenberger, H., \& Tandoc, E. (2014). Updated Statuses: Understanding Facebook Use Through Explicit and Implicit Measures of Attitudes and Motivations. Online Journal of Communication and Media Technologies, 4(1), 217-244.

Steeves, V., \& Regan, P. (2014).Young people online and the social value of privacy. Journal of Information, Communication \& Ethics in Society, 12(4), 298. Retrieved from http://rose.scranton.edu.ezp.scranton.edu/login?url=http:// search.proquest.com.ezp.scranton.edu/docview/1642189467?accountid=28588

Thorne, A. (2015). Social Media, Civility, and Free Expression.Academic Questions. 28(3), 334338. https://doi.org/10.1007/s12129-015-9516-X

Viera, A. J., \& Garrett, J. M. (2005). Understanding inter-observer agreement: The Kappa statistic. Family Medicine, 37(5), 360-363. 
Yang, C., \& Brown, B. B. (2013). Motives for Using Facebook, Patterns of Facebook Activities, and Late Adolescents' Social Adjustment to College. Journal of Youth and Adolescence, 42(3), 403-416. https://doi.org/10.1007/s10964-012-9836-X

Wolfer, L. (2016). No Social Issues, Sex or Politics on Facebook: Young Adults' Views of Inappropriate Facebook Posts. The International Journal of Social Sciences and Humanities Invention, 3(10), 2860-2867. https://doi.org/10.18535/ijsshi/v3i10.07 